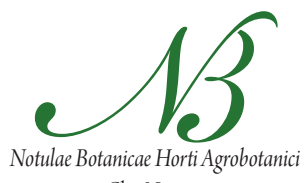

Clij-Napoca

\title{
Quantitative Determination of Arbutin and Hydroquinone in Different Plant Materials by HPLC
}

\author{
Izabela RYCHLINSKA, Slawomira NOWAK \\ Medical University of Łódź, Department of Pharmacognosy, 1 Muszyńskiego Str., 90-151 Łódź, \\ Poland;izabela.rychlinska@umed.lodz.pl,slawomira.nowak@umed.lodz.pl
}

\begin{abstract}
A simple, fast method of high-performance liquid chromatography for the determination and quantification of arbutin and hydroquinone in many different raw materials was developed and validated. The optimum conditions for the separation and detection of these two constituents were achieved on a LiChro-CARD 125-4 Superspher 100 RP-18 column with the water-methanol (gradient elution) mobile phase and recorded at $289 \mathrm{~nm}$. The purities of peaks were verified by PDA analysis of impurities. The results of validation have shown that the HPLC method is stable and accurate for the simultaneous determination of arbutin and hydroquinone in extracts from various plants. The developed method gave a good sensitivity (LOD $1 \mu \mathrm{g} / \mathrm{ml}$ for arbutin and $0.49 \mu \mathrm{g} / \mathrm{ml}$ for hydroquinone) with linearity $\mathrm{R}^{2}>0.9993$ (for both). The relative standard deviation of the method was less than $2.53 \%$ for intra-day assays and $3.23 \%$ for inter-day assay, the accuracy of the recovery test ranged from $98.96 \%$ to $106.4 \%$. This method was used in comparative qualitative analysis of arbutin and hydroquinone in 16 different raw materials from families Lamiaceae, Ericacaeae, Saxifragaceae, Rosaceae. The content of arbutin in B. ciliata, B. cordifolia and Ledum palustre was examined for the first time.
\end{abstract}

Keywords: arbutin, hydroquinone, quantitative analysis, RP-HPLC

\section{Introduction}

Arbutin (4-hydroxyphenol $\beta$-D-glucopyranoside) is a derivative of hydroquinone and belongs to the group of simple phenols. Arbutin occurs naturally in plants and high quantities of it were found in plant families such as: Lamiaceae, Ericaceae, Saxifragaceae and Rosaceae. From the pharmacological point of view it is of interest due to two therapeutic applications. The antibacterial properties recommend using the plants Uvae ursi folium (Ph. Eur. $6^{\text {th }}$ ed., Polish Ph. VIII) and Vitis idaeae folium (Polish Ph. VI) for the treatment of urogenital tract infections. The theory of antibacterial properties of arbutin were formulated by Lewin already in 1883 (Dingermann et al., 2004; European Pharmacopoeia, 2008; Evans, 2009; Hänsel et al., 1999; Nycz et al., 2010; Polish Pharmacopeia, 2002, 2008; Wichtl, 2004).

Arbutin has also the property of suppressing melanin biosynthesis in human skin and it is used in treating skin discolorations such as melasma, freckles, hyperpigmentation or other disorders, as well as in the cosmetic industry (Hu et al., 2009).

Arbutin and its aglycone were found in animal studies to have hepatotoxic, nephrotoxic, mutagenic and carcinogenic effects. Therefore, the use of products containing hydroquinone glycosides by patients should be strictly controlled. According to the Commission E, preparations containing arbutin should not be taken for more than one a week and a maximum of 5 times per year, and only at the consent of a physician. Preparations are not recommend- ed especially for pregnant women and nursing mothers (Dingermann et al., 2004; Hänsel et al., 1999). The presence of arbutin in plant materials can be regarded as undesirable in the human diet. However, in the context that arbutin is common in our daily diet (pears, cereal, spices etc.) intake of arbutin should be monitored and limited (Lukas et al., 2010).

The content of arbutin was determined in plant extracts by many methods: spectrophotometric (Pavlović et al., 2009), capillary zone electrophoresis (Glöckl et al., 2001), densitometric (Pyka et al., 2007), GC/MS (Lamien-Meda et al., 2009). Reversed-phase HPLC was found to be the more suitable chromatographic method for arbutin separation (Asaaf et al., 1986; Parejo et al., 2001; Pavlović et al., 2009). To our knowledge, there is no single validated HPLC method which was developed for the quantification of arbutin in many different plant extracts.

In the present work, conditions of extraction and chromatographic parameters have been combined in order to establish a simpler, faster and cheaper method for the extraction and HPLC determination of arbutin in a variety of raw materials. Additional experiments were carried out in order to determine the effect of the extraction solvent on the peak resolution of arbutin by HPLC.

A comparative study of the contents of arbutin and hydroquinone was performed on 16 different plant species from the families: Lamiaceae, Ericaceae, Saxifragaceae, Rosaceae. Selected raw materials for testing are widely used as medication and spices. 
110

\section{Materials and methods}

\section{Plant materials}

Dried plant materials used in the quantitative determinations: herbs of Majorana hortensis (I), Thymus vulgaris (II), Thymus serpyllum (III), Origanum vulgare (IV) and leaves of Arctostaphylos uva-ursi (V), Vaccinium vitis idaea (VI), Vaccinium myrtillus (VII) and flowers of Calluna vulgaris (VIII), were purchased from the pharmaceutical company Kawon (Poland), GMP and ISO 9002 certified. Other samples were obtained from the Botanical Garden in Łódź: leaves of Vaccinium uliginosum (IX), Ledum palustre (X), Bergenia crassifolia (XI), Bergenia cordifolia (XII), Bergenia ciliata (XIII), Bergenia purpurascens (XIV), Pyrus communis (XV) and flowers of Pyrus communis (XVI). Authenticated voucher specimens (I-XVI) have been deposited in the herbarium collection of the Department of Pharmacognosy, Medical University of Łódź.

Plant materials were dried at room temperature, powdered and passed through a $0.315 \mathrm{~nm}$ sieve in order to produce a homogeneous powder for the analyses.

\section{Chemicals and reagents}

HPLC-grade gradient methanol (J. T. Baker, Holland), deionized water and orthophosphoric acid (Merck, Germany) were used in HPLC analyses. Methanol (POCh, Poland) and deionized water were used for extraction procedures. The standards of arbutin and hydroquinone were purchased from Roth (Germany).

\section{Samples preparation}

The different amounts of plant material used in the tests depended on the expected contents of arbutin. Accurately weighted masses of the samples (sources I, XI, XII, XIII, XV, XVI - $0.4 \mathrm{~g}$, sources V,VI, X - $0.2 \mathrm{~g}$, sources II, III, IV, VII,VIII, IX, XIV - $0.8 \mathrm{~g}$ ) were heated twice for $30 \mathrm{~min}$, with $20 \mathrm{ml}$ of water added each time, in a boiling water bath under reflux. The combination of the extracts of these 2 heating processes were diluted to $50 \mathrm{ml}$ with water and filtered through a PTFE filter $(13 \mathrm{~mm}, 2 \mu \mathrm{m}$, Whatman). In order to examine the effect of the eluent on the separation of the arbutin and hydroquinone peaks, extracts from raw materials I, V, VI and X, in methanol and water:methanol (50:50) were prepared in the same way.

For each of the studied plant materials two extracts were made and each of them as a prepared solution $(20 \mu \mathrm{l})$ was injected three times into the HPLC system. Thus the value obtained for each sample is the mean of six HPLC analyses. Samples were quantified immediately after extraction in order to avoid possible chemical alterations.

\section{Apparatus and HPLC conditions}

HPLC equipment: Hewlett Packard 1100 series Liquid Chromatograph with quaternary pump, UV-VIS detector. The column: LiChro-CARD 125-4 Superspher ${ }^{\circ} 100$ RP18.

The mobile phase comprised: $0.5 \%$ water solution of ortophosphoric acid, methanol. Elution profile: 0-2 min.: 0-2\% methanol, 2.01-6 min.: 15\% methanol, 6.01-8 min.: 15-25\% methanol, 8.01-12 min.: 70\% methanol. The flow rate $1 \mathrm{ml} / \mathrm{min}$., detection: $\lambda=289 \mathrm{~nm}$, injection volume: $20 \mu \mathrm{l}$, maintained at room temperature. Each run was followed by an equilibration period $3 \mathrm{~min}$.

The analytes were identified by comparison of their retention times and UV spectra with those of the standard. The purities of peaks were verified by PDA analysis of impurities. The identification was performed using Waters 600E Multisolvent Delivery System (Waters Co., MA, USA) with a photodiode array detector (PDA 996 Waters) working in the range of 190-800 $\mathrm{nm}$.

\section{Method validation}

The analytical HPLC method was validated in terms of linearity, precision, accuracy and stability.

\section{Standard solution and calibration curves}

Standard stock solution in water of both arbutin and hydroquinone were prepared at the final concentration of $500 \mu \mathrm{g} / \mathrm{ml}$ for arbutin and $140 \mu \mathrm{g} / \mathrm{ml}$ for hydroquinone. Before calibration the stock solution was diluted with water. The standard curve was prepared over a concentration range of $7.5-500 \mu \mathrm{g} / \mathrm{ml}$ for arbutin and $1.4-98 \mu \mathrm{g} / \mathrm{ml}$ for hydroquinone with six different concentration levels. Linearity for arbutin and hydroquinone was plotted using linear regression of the peak area versus concentration. The coefficient of correlation $\left(\mathrm{R}^{2}\right)$ was used to judge the linearity. The detection limits (LOD) and quantitation limits (LOQ) for tested compounds were determined by the signal-to-noise $(\mathrm{S} / \mathrm{N})$ ratio. Analyzing a series of diluted standard solutions the $\mathrm{S} / \mathrm{N}$ ratios 3 and 10 , respectively, were obtained, based on a $20 \mu$ injection (Tab. 1).

The precision of the method was evaluated by measurement in intra-day and inter-day variability tests. The repeatability was examined using a standard solution and real sample extract of Pyrus communis flos (XVI). The intra- and inter-day precision were determined by estimating the corresponding response five times on the same day and on three different days, respectively. The values of the

Tab. 1. Linearity of standard curves and limits of detection LOD and limits of quantitation LOQ

\begin{tabular}{cccccc}
\hline Compound & $\begin{array}{c}\text { Linear range } \\
(\mu \mathrm{g} / \mathrm{ml})\end{array}$ & $\begin{array}{c}\text { Calibration equation } \\
\text { a }\end{array}$ & $\begin{array}{c}\text { Correlation factor } \mathrm{R}^{2} \\
(\mathrm{n}=6)\end{array}$ & $\begin{array}{c}\text { LOD } \\
(\mu \mathrm{g} / \mathrm{ml})\end{array}$ & $\begin{array}{c}\text { LOQ } \\
(\mu \mathrm{g} / \mathrm{ml})\end{array}$ \\
\hline Arbutin & $7.5-500$ & $\mathrm{y}=49248 \mathrm{x}-250$ & 0.9997 & 1.01 & 3.07 \\
Hydroquinone & $1.4-98$ & $\mathrm{y}=189489 \mathrm{x}-97367$ & 0.9993 & 0.49 & 1.50 \\
\hline
\end{tabular}

${ }^{a}$ In the calibration equation, $\mathrm{x}$ is concentration of the compounds solution in $\mu \mathrm{g} / \mathrm{ml}$ and $\mathrm{y}$ is peak area of the compound 
relative standard deviation were considered as a measure of precision and calculated for both retention time and integration area (Tab. 2).

The accuracy of this method was verified by the recovery test. The recovery test was accomplished by adding standard solutions in three different concentrations $(0.25$, $0.5,1 \mathrm{mg}$ for arbutin and $0.07,0.14,0.28 \mathrm{mg}$ for hydroquinone to a known quantity of the extract of Pyrus communis flos (XVI) (Tab. 3).

\section{Results and discussion}

\section{Optimization of HPLC conditions}

The selection of HPLC conditions was carried out to a good separation of arbutin and hydroquinone in 16 different plant extracts (I-XVI). The mobile phase (consisting of water and methanol) is very favorable, because its use resulted in short time analysis (good retention times $3.36 \mathrm{~min}$ for arbutin and $3.9 \mathrm{~min}$ for hydroquinone) and single symmetrical peaks resolution for tested compounds. The conditions of HPLC analysis were the most suitable for good results, because they are easily reproduced for all tested plant extracts and the time of reequilibrating the column between injections is short. The detector wavelength was set according to the maximum absorption wavelength in the UV spectrum for arbutin and hydroquinone 289 $\mathrm{nm}$. The peak identity was confirmed by comparison of the retention time and UV spectrum of each tested compound (HPLC with PDA detector).

\section{Optimization of sample preparation}

In order to complete the extraction of arbutin, three different extracts in water, methanol, water-methanol 50:50 were prepared from plant material I, V, VI and X. On the basis of the peak-area responses, water was found to be the best solvent yielding the highest concentrations of the tested compounds. The use of solvents other than water resulted in severe peak distortions. The optimum method of extraction combined water as a solvent and heating under a reflux condenser in a water bath for 30 min. (Ph. Eur. $7^{\text {th }}$ ed., 2011) (Fig. 1).

\section{Linearity, precision, accuracy and stability}

Correlation coefficient $\left(\mathrm{R}^{2}\right)$ values for arbutin 0.9997 and for hydroquinone 0.9993 indicated good linearity. LOD was estimated to be $1 \mu \mathrm{g} / \mathrm{ml}$ for arbutin and 0.49 $\mu \mathrm{g} / \mathrm{ml}$ for hydroquinone. In comparison with reported methods, our chromatographic protocol described above showed higher sensitivity and precision than the HPLC method of Fecka (Fecka and Turek, 2008) and Kittipongpatana (Kittipongpatana et al., 2007), where the limit of detection for arbutin was $4.5 \mu \mathrm{g} / \mathrm{ml}$ and $5 \mu \mathrm{g} / \mathrm{ml}$, respectively (Tab. 1).

The results shown in Tab. 2 and 3 indicate that the developed analytical method was reproducible with good recovery and stability. The intra- and inter-day variations RSD for arbutin and hydroquinone were less than 3.23\% and $3.27 \%$, respectively. The higher values of RSD were observed for the real samples than standard solutions. The values of relative standard deviation for retention times of real samples and the standard solution were low.

The average recoveries, determined during the standard addition procedure, were very satisfactory, thereby confirming the accuracy and robustness of this analytical method. Recovery rates for arbutin between $98.96 \%$ and $101.82 \%$ and for hydroquinone between $104.18 \%$ and $106.4 \%$ were obtained, and their RSD values were between $0.36 \%$ and $1.07 \%$ and between $0.19 \%$ and $4.73 \%$, respectively (Tab. 3).

Tab. 2. Retention parameters and analytical results of intra-day and inter-day tests for standard solutions and Pyrus communis flowers (source XVI)

\begin{tabular}{|c|c|c|c|c|c|c|c|c|c|}
\hline \multirow{3}{*}{ Compound } & \multirow{3}{*}{$\begin{array}{l}\text { Retention time } \\
\text { RT }(\min )^{a}\end{array}$} & \multicolumn{4}{|c|}{ Intra-day variability R.S.D. (\%) } & \multicolumn{4}{|c|}{ Inter-day variability RSD $(\%)^{a}$} \\
\hline & & \multicolumn{2}{|c|}{ Standard solution } & \multicolumn{2}{|c|}{ Real sample } & \multicolumn{2}{|c|}{ Standard solution } & \multicolumn{2}{|c|}{ Real sample } \\
\hline & & RT & Peak area & RT & Peak area & RT & Peak area & RT & Peak area \\
\hline Arbutin & 3.36 & 0.15 & 1.55 & 0.13 & 2.11 & 0.18 & 1.36 & 0.33 & 3.23 \\
\hline Hydroquinone & 3.93 & 0.08 & 2.53 & 0.08 & 3.27 & 0.23 & 2.52 & 0.32 & 3.10 \\
\hline
\end{tabular}

${ }^{a}$ Mean values for standard solution and real samples tested for inter-day variability $(n=9)$; RSD - relative standard deviation in $\%(n=9)$

Tab. 3. Recoveries of arbutin and hydroquinone in the extracts of Pyrus communis flowers (source XVI)

\begin{tabular}{|c|c|c|c|c|c|c|}
\hline \multirow{2}{*}{ Compound } & \multirow{2}{*}{$\begin{array}{l}\text { Initial concentration } \\
\text { in the extract }(\mu \mathrm{g} / 1 \mathrm{ml})\end{array}$} & \multirow{2}{*}{$\begin{array}{c}\text { Amount } \\
\text { added }(\mu \mathrm{g})\end{array}$} & \multicolumn{2}{|c|}{ Concentration after addition $(\mu \mathrm{g} / 1 \mathrm{ml})^{\mathrm{a}}$} & \multirow{2}{*}{ Recovery (\%) } & \multirow{2}{*}{$\operatorname{RSD}(\%)$} \\
\hline & & & Expected & Measured & & \\
\hline \multirow{3}{*}{ Arbutin } & \multirow{3}{*}{91.52} & 250 & 116.52 & 115.31 & 98.96 & 0.36 \\
\hline & & 500 & 141.52 & 144.09 & 101.82 & 1.07 \\
\hline & & 1000 & 191.52 & 193.14 & 100.85 & 0.46 \\
\hline \multirow{3}{*}{ Hydroquinone } & \multirow{3}{*}{31.75} & 70 & 38.75 & 40.37 & 104.18 & 0.19 \\
\hline & & 140 & 45.75 & 47.90 & 104.70 & 4.73 \\
\hline & & 280 & 59.75 & 63.92 & 106.40 & 3.74 \\
\hline
\end{tabular}

${ }^{\mathrm{a}}$ Mean values concentration of the compounds in the final analytical solution $(\mathrm{n}=5) ;{ }^{\mathrm{b}} \mathrm{RSD}$ values for $\mathrm{n}=5$ 

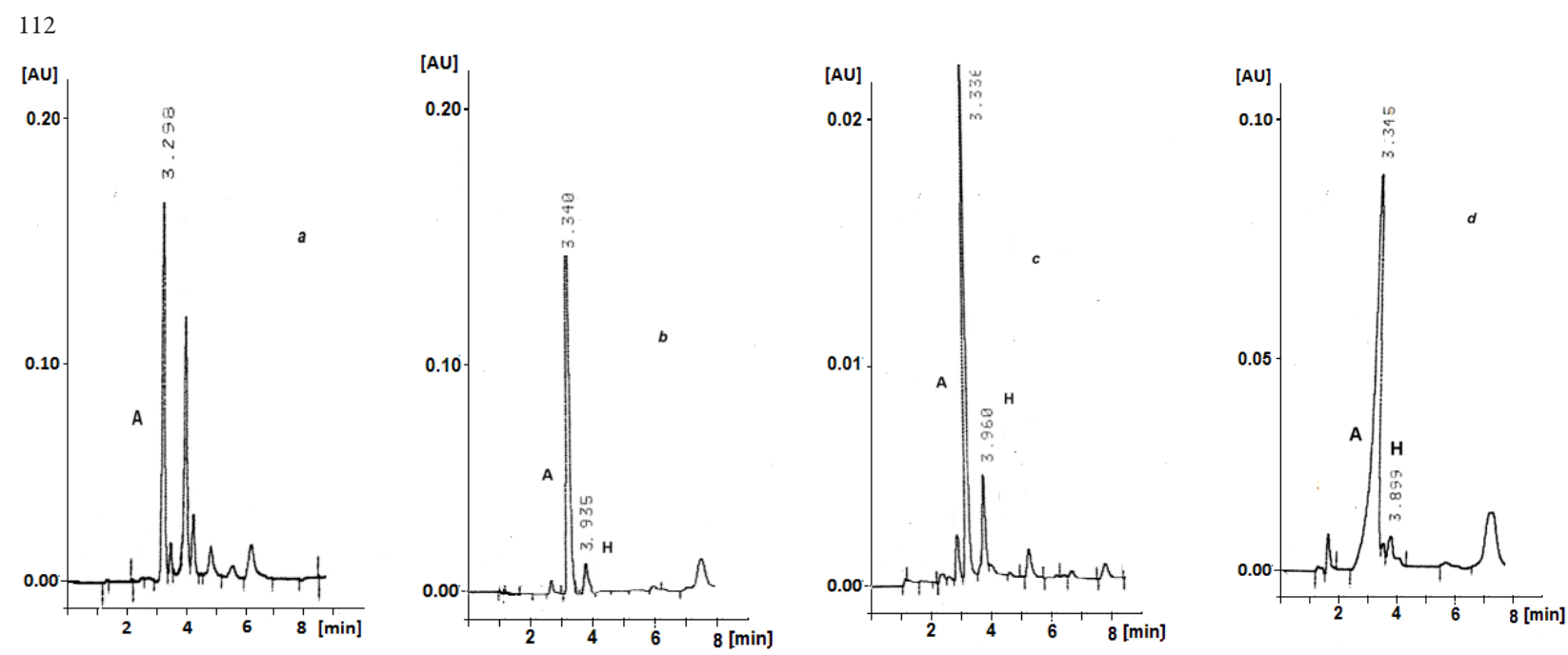

Fig 1. Representative HPLC chromatograms: water extract of a) B. crassifolia, b) A. uva-ursi, c) Majorana hortensis and d) methanol extract of $A$. uva-ursi

HPLC analysis of arbutin in plant extract

Comparative study of the contents of arbutin and hydroquinone by high performance liquid chromatography (HPLC) were carried out in 16 different plant species from the families: Lamiaceae, Ericaceae, Saxifragaceae, Rosaceae. Raw materials selected for testing are widely used in medicine as medication (I-VII, IX, XV, XVI) and in everyday life as spices (I-IV) and were obtained from the pharmaceutical company Kawon and the Botanical Garden in Łódź, so the purity of species of plants tested is ensured. The purity of peaks of arbutin and hydroquinone has been verified by PDA analysis in all tested plant extracts. The content of analyzed compounds has been expressed as $\mathrm{mg} / \mathrm{g}$ of dried weight herb and is presented in Tab. 4.

Among the studied plants the highest content of arbutin was found in Bergenia crassifolia leaves $(122.29 \mathrm{mg} / \mathrm{g}$ ) and the lowest in Ledum palustre herb (1.56 mg/g). Most of our results are comparable to literature data for selected

Tab. 4. Content of arbutin and hydroquinone in I-XVI samples plant materials (European Pharmacopoeia, 2008; Fecka and Turek, 2008; Jiang Hongjun et al., 2010; Lukas et al., 2010; Pavlović et al., 2009; Sticher et al.,1979; Polish Pharmacopeia, 2002, 2008; Pop et al., 2009; Rychlinska and Gudej, 2003). The content of arbutin in Bergenia crassifolia leaves is $15-20 \%$ according to Pop et al. (2009) and in Bergenia purpurascens leaves is $1.51-6.36 \%$ according to Jiang Hongjun et al. (2010). Some differences in the content of arbutin may result from different raw material drying methods (Jiang Hongjun et al., 2010; Pop et al., 2009). The content of arbutin in Majorana hortensis herb varies from $11.1 \mathrm{mg} / \mathrm{g}$ to $118 \mathrm{mg} / \mathrm{g}$ according to Lukas et al. (2010) and from $12.71 \mathrm{mg} / \mathrm{g}$ to $60.45 \mathrm{mg} / \mathrm{g}$ according to Fecka and Turek (2008), while this study has given 17.24 $\mathrm{mg} / \mathrm{g}$. Earlier study of arbutin content in Pyrus communis flowers has given the result of $14 \mathrm{mg} / \mathrm{g}$, which is similar to the result described in Tab. 4 (Rychlinska and Gudej, 2003). This study has confirmed the absence of arbutin

\begin{tabular}{|c|c|c|c|c|c|c|}
\hline \multirow{2}{*}{$\begin{array}{c}\text { Sample } \\
\text { Nr. }\end{array}$} & \multirow{2}{*}{ Species } & \multirow{2}{*}{ Part } & \multicolumn{2}{|c|}{ Arbutin } & \multicolumn{2}{|c|}{ Hydroquinone } \\
\hline & & & $X(\mathrm{mg} / \mathrm{g}) \pm \mathrm{SD}^{\mathrm{a}}$ & $\mathrm{RSD}(\%)$ & $\mathrm{X}(\mathrm{mg} / \mathrm{g}) \pm \mathrm{SD}^{\mathrm{a}}$ & $\mathrm{RSD}(\%)$ \\
\hline I & Majorana hortensis & Herb & $17.24 \pm 0.36$ & 2.07 & $0.99 \pm 0.012$ & 1.09 \\
\hline II & Thymus vulgaris & Herb & n.d. & --- & n.d. & \\
\hline III & Thymus serpyllum & Herb & n.d. & -.- & n.d. & \\
\hline IV & Origanum vulgare & Herb & n.d. & -.- & n.d. & -.- \\
\hline V & A. uva-ursi & Leaves & $90.48 \pm 1.98$ & 2.18 & $1.93 \pm 0.049$ & 2.54 \\
\hline VI & V.vitis idaea & Leaves & $51.68 \pm 0.48$ & 0.92 & $1.08 \pm 0.016$ & 1.48 \\
\hline VII & V.myrtillus & Leaves & n.d & -.- & n.d. &.-- \\
\hline VIII & V. uliginosum & Leaves & n.d. & --- & n.d. & --- \\
\hline IX & Calluna vulgaris & Flowers & n.d. & -.- & n.d. & -.- \\
\hline $\mathrm{X}$ & Ledum palustre & Herb & $1.56 \pm 0.04$ & 2.40 & n.d. & -.. \\
\hline XI & B. crassifolia & Leaves & $122.29 \pm 2.23$ & 1.82 & n.d. & -.- \\
\hline XII & B. cordifolia & Leaves & $23.46 \pm 0.21$ & 0.91 & n.d. & -.- \\
\hline XIII & B. ciliata & Leaves & $13.57 \pm 0.20$ & 1.51 & n.d. & -.- \\
\hline XIV & B. purpurascens & Leaves & $16.08 \pm 0.76$ & 4.75 & n.d. & -.- \\
\hline $\mathrm{XV}$ & Pyrus communis & Leaves & $24.89 \pm 0.47$ & 1.91 & $0.87 \pm 0.02$ & 2.41 \\
\hline XVI & Pyrus communis & Flowers & $14.13 \pm 0.28$ & 2.02 & $3.73 \pm 0.03$ & 0.83 \\
\hline
\end{tabular}

${ }^{\mathrm{a}}$ Mean arbutin and hydroquinone content in plant material \pm SD (standard deviation) in $\mathrm{mg} / \mathrm{g}$ dry weight $(\mathrm{n}=6)$; n.d. - peak not detected 
in Thymus sepyllum, Origanum vulgare, Vaccinium mytillus, Vaccinium uliginosum and Calluna vulgaris. The absence of arbutin in the above mentioned raw materials is reported by Sticher et al.(1979), Lukas et al. (2010), Fecka and Turek (2008). The study has also shown the lack of this substance in Thymus vulgaris herb. This last result differs from literature data, which in most cases reports the presence of arbutin in Thymus vulgaris but only in small amounts of $0.06-0.11 \%$ (Fecka and Turek, 2008). Quantitative determination of arbutin by HPLC method in $B$. ciliata, B. cordifolia and Ledum palustre was conducted for the first time.

The content of hydroquinone was specified in only five plant materials and the highest was in Pyrus communis flos (3.73 mg/g).

\section{Conclusion}

In the present work, conditions of extraction and chromatographic parameters have been combined in order to establish a faster and cheaper method for the extraction and HPLC determination of arbutin in different raw materials. Water was found to be the best solvent yielding the highest concentrations of the tested compounds. The developed RP-HPLC method is simple, rapid, accurate and reproducible for detection and quantification of arbutin and hydroquinone in plant extracts. A good separation of arbutin and hydroquinone (single symmetrical peaks) from the other components in the plant was obtained within $3.36 \mathrm{~min}$ and $3.93 \mathrm{~min}$, respectively. The purity of peaks of arbutin and hydroquinone has been verified by PDA analysis in all tested plant extracts. The assay is reproducible, sensitive, fully validated and was successfully applied to extracts of 16 different plants from families $L a$ miaceae, Ericaceae, Saxifragaceae, Rosaceae. Raw materials selected for testing are widely used both in medicine as medication and in everyday life as spices.

Furthermore, the method can be used for quality control of arbutin in other plants. Considering the bioactivity of arbutin, its presence in the human diet can be regarded as undesirable, therefore, the dietary intake of arbutin should be monitored and limited.

\section{References}

Asaaf M, Ali A, Makboul M, Beck JP, Anton R (1986). Preliminary study of phenolic glycosides from Origanum majorana; quantitative estimation of arbutin; cytotoxic activity of hydroquinone. Planta Med 53:343-345.

Dingermann T, Hiller K, Zündorf I, Schneider G (2004). Arzneidrogen 5. Auflage. Elsevier Spekt Akadem Verlag.

European Pharmacopoeia. $6^{\text {th }} \mathrm{ed} .2008$.

Evans W (2009). Pharmacognosy 16th Edition. Saunders Elsevier, Edinburg, London, NY, St Louis, Sidney, Toronto.

Fecka I, Turek S (2008). Determination of polyphenolic compounds incommercial herbal drugs and spices from Lamiaceae: thyme, wild thyme and sweet marjoram by chromatographic techniques. Food Chem 108:1039-1053.

Glöckl I, Blaschke G, Veit M (2001). Validated methods for direct determination of hydroquinone glucuronide and sulfate in human urine after oral intake of bearberry leaf extract by capillary zone electrophoresis. J Chromatogr B: Biomed Sci Appl 761(2):261-266.

Hänsel R, Sticher O, Steinegger E (1999). PharmakognosiePhytopharmazie. Springer Verlag Berlin.

$\mathrm{Hu}$ Z, Zhou Q, LeiT, Ding S, Xu S (2009). Effects of hydroquinone and its derivatives on melanogenesis and antioxidation: Biosafety as skin whitening agents. J Dermatol Sci 55:179-184.

Jiang H, Guo F, Zhang L, Chen Y, Li S, Yang F (2010). Comparison of arbutin contents from Bergenia purpurascens in Yunnan. China J Materia Medica 35(14):1812-1814.

Lamien-Meda A, Lukas B, Schmiderer C, Franz Ch, Novak J (2009). Validation of a quantitative assay of arbutin using gas chromatography in Origanum Majorana and Arctostaphylos uva-ursi extracts. Phytochem Anal 20:416-420.

Lukas B, Schmiderer C, Mitteregger U, NovakJ (2010). Arbutin in marjoram and oregano. Food Chem 121:185-190.

Nisit K, Aueporn C, Umaporn P, Ornanong SK (2007). High-Performance Liquid Chromatographic Method for Separation and Quantitative Analysis of Arbutin in Plant Tissue Cultures. CMU J Nat Sci 6(1):65.

Nycz J, Malecki G, Morag M, Nowak G, Ponikiewski L, Kusz J, Switlicka A (2010). Arbutin: Isolation, X-ray structure and computional studies. J Mol Struct 980:13-17.

Parejo I, Viladomat F, Bastida J, Codina C (2001). A single extraction step in the quantitative analysis of arbutin in bearberry (Arctostaphylos uva-ursi) leaves by HPLC. Phytochem Anal 12(5):336-339.

Pavlović R.D, Lakušić B, Došlov-Kokoruš Z, Kovačević N (2009). Arbutin content and antioxidant activity of some Ericaceae species. Pharmazie 64:656-659.

Polish Pharmacopeia $6^{\text {th }}$ Ed. Polish Pharmaceutical Society (Eds.) Warsaw 2002-2008.

Pop C, Vlase L, Tamas M (2009). Natural resources containing arbutin. Determination of arbutin in the leaves of Bergenia crassifolia (1.) fritsch. acclimated in Romania. Not Bot Horti Agrobo 37(1):129-132.

Pyka A, Bober K, Stolarczyk A (2007). Densitometric determination of arbutinin cowberry leaves (Vaccinium Vitis-idaeae). Acta Pol Pharm 63(5):395-400.

Rychlinska I, Gudej J (2003). Quantitative and qualitative chromatographic investigation of hydroquinone derivatives in Pyrus communis L. flowers. Acta Pol 60:309-312.

Sticher O, Soldati F, Lehmann D (1979). High-performance liquid chromatography separation and quantitative determination of arbutin, methylarbutin, hydroquinone and hydroquinone-monomethyether in Arctostaphylos, Bergenia, Calluna and Vaccinium species. Planta Medica 35:253-261.

Wichtl M (2004). Herbal Drugs and Phytopharmaceuticals. A Handbook for Practice on a Scientific Basis. $3^{\text {rd }}$ Edition. Medpharm Scientific Publishers Stuttgart. 